\title{
Two Isostructural Coordination Polymers Showing Diverse Magnetic Behaviors: Weak Coupling (Ni") and an Ordered Array of Single-Chain Magnets (Co")
}

\author{
Min Chen,${ }^{\dagger}$ Hui Zhao, ${ }^{\dagger}$ E. Carolina Sañudo, ${ }^{\ddagger}$ Chun-Sen Liu, ${ }^{*, \dagger}$ and Miao Du ${ }^{*,+, \S}$ \\ ${ }^{\dagger}$ Henan Provincial Key Lab of Surface \& Interface Science, Zhengzhou 450002, Henan, Peoples' Republic of China \\ ${ }^{\ddagger}$ Departament de Química Inorgàiza i Institut de Nanociènia i Nanotecnologia, Universitat de Barcelona, Diagonal 645, 08028 \\ Barcelona, Spain \\ ${ }^{\S}$ College of Chemistry, Tianjin Key Laboratory of Structure and Performance for Functional Molecules, MOE Key Laboratory of \\ Inorganic-Organic Hybrid Functional Material Chemistry, Tianjin Normal University, Tianjin 300387, Peoples' Republic of China \\ * Supporting Information
}

ABSTRACT: Two isomorphic 3-D complexes with the formulas $\left[\mathrm{M}_{3} \text { (TPTA) }(\mathrm{OH})_{2}\left(\mathrm{H}_{2} \mathrm{O}\right)_{4}\right]_{n}(\mathrm{M}=\mathrm{Ni}$ for 1 and Co for $2 ; \mathrm{H}_{4}$ TPTA $=\left[1,1^{\prime}: 4^{\prime}, 1^{\prime \prime}\right.$-terphenyl $]-2^{\prime}, 3,3^{\prime \prime}, 5^{\prime}$ tetracarboxylic acid) have been synthesized and magnetically characterized. Complexes $1\left(\mathrm{Ni}^{\mathrm{II}}\right)$ and $2\left(\mathrm{Co}^{\mathrm{II}}\right)$ have the same 1-D rod-shaped inorganic SBUs but exhibit significantly different magnetic properties. Complex $2\left(\mathrm{Co}^{\mathrm{II}}\right)$ is a $3-\mathrm{D}$ arrangement of a $1-\mathrm{D} \mathrm{Co}{ }^{\mathrm{II}}$ single-chain magnet $(\mathrm{SCM})$, while complex $1\left(\mathrm{Ni}^{\mathrm{II}}\right)$ exhibits weak coupling.

Molecular-based magnetic materials have attracted significant interest because of their distinctive finite size, lower energy consumption, less relative density, and structural diversity. ${ }^{1,2}$ Among them, SCMs (single-chain magnets) featuring quantum tunneling and slow relaxation of magnetization are becoming hot topics. On the basis of Glauber's theory, ${ }^{3}$ the slow magnetic relaxation was rooted in three points: (i) large uniaxial type magnetic anisotropy, (ii) strong intrachain magnetic interaction, and (iii) the 3-D magnetic ordering. In this context, the most important feature of the organic linker is to ensure that the magnetic information will be efficiently relayed along the chain. Nevertheless, utilizing appropriate carboxylate ligands as efficient magnetic couplers to connect anisotropic and uniaxial spin metal ions (such as $\mathrm{Co}^{\mathrm{II}}, \mathrm{Ni}^{\mathrm{II}}, \mathrm{Mn}^{\mathrm{III}}, \mathrm{Fe}^{\mathrm{II}}$, or lanthanide ions) into 1-D chains is a feasible strategy to obtain such materials exhibiting SCM behavior, which has been demonstrated in the majority of the reported SCMs ${ }^{4-8}$ Additionally, embedding 1-D Ising ferro- or antiferromagnetic chains into 2$\mathrm{D}$ or 3-D networks and tuning interchain interactions in the crystal packing through suitable diamagnetic separators might be another alternative strategy to synthesize SCMs. ${ }^{9,10}$ Herein, we selected an asymmetrical tetra-carboxylate ligand, [1, 1':4', 1"-terphenyl]-2',3,3",5'-tetracarboxylic acid ( $\mathrm{H}_{4}$ TPTA, see Scheme S1 in the Supporting Information, SI), ${ }^{11}$ to react with $\mathrm{Co}^{\mathrm{II}}$ and $\mathrm{Ni}^{\mathrm{II}}$, and two isostructural complexes $\left[\mathrm{M}_{3} \text { (TPTA) }(\mathrm{OH})_{2}\left(\mathrm{H}_{2} \mathrm{O}\right)_{4}\right]_{n}(\mathrm{M}=\mathrm{Ni}$ for 1 and $\mathrm{Co}$ for 2$)$ were obtained. The structure and magnetic analyses reveal that the 1-D rod-shaped SBUs with the large anisotropy of the $\mathrm{Co}^{\mathrm{II}}$ ions in 2 lead to a slow magnetized relaxation phenomenon, and the long bridging TPTA ligands link 1-D magnetic nanowires into a 3-D network as well as their weak commutation of the spin carriers. Meanwhile, complex $1\left(\mathrm{Ni}^{\mathrm{II}}\right)$ shows the same 3-D framework constructed by weakly coupled 1-D rod-shaped SBUs of $\mathrm{Ni}^{\mathrm{II}}$ ions

The hydrothermal reaction of $\mathrm{M}\left(\mathrm{NO}_{3}\right)_{3} \cdot 6 \mathrm{H}_{2} \mathrm{O}(\mathrm{M}=\mathrm{Ni}$ for 1 and $\mathrm{Co}$ for 2 ) and $\mathrm{H}_{4}$ TPTA in water produces block crystals of $1\left(\mathrm{Ni}^{\mathrm{II}}\right)$ and $2\left(\mathrm{Co}^{\mathrm{II}}\right)$ (see the SI for details). Single-crystal X-ray diffraction analysis indicates that complexes $1\left(\mathrm{Ni}^{\mathrm{II}}\right)$ and $2\left(\mathrm{Co}^{\mathrm{II}}\right)$ are isomorphous and isostructural (Table $\mathrm{S} 1$ in the $\mathrm{SI}$ ); therefore, $2\left(\mathrm{Co}^{\mathrm{II}}\right)$ is used for detailed structural description. The asymmetric coordination units for $2\left(\mathrm{Co}^{\mathrm{II}}\right)$ consist of two crystallographic independent $\mathrm{Co}^{\mathrm{II}}$ ions (with 1.0 and 0.5 occupancy, respectively), one TPTA, two hydroxyl, and four coordinated water ligands (Figure S3 in the SI). The Co1 and $\mathrm{Co} 2$ centers are octahedrally coordinated to six oxygen atoms. Each $\mu_{2}$-carboxylate group in the fully deprotonated TPTA ligand connects two Co ${ }^{\mathrm{II}}$ ions (Figure S4 in the SI). Notablely, the three phenyl rings of the TPTA ligand are not coplanar with the dihedral angle of $60.5^{\circ}$ in $2\left(\mathrm{Co}^{\mathrm{II}}\right)$ and $60.9^{\circ}$ in $1\left(\mathrm{Ni}^{\mathrm{II}}\right)$, respectively(Figure S5 and Table S3 in the SI). Meanwhile, the dihedral angles between the carboxylate groups and adjacent linking phenyl rings of TPTA are $51.8 / 16.8^{\circ}$ in $2\left(\mathrm{Co}^{\mathrm{II}}\right)$ and $50.5 / 18.8^{\circ}$ for $1\left(\mathrm{Ni}^{\mathrm{II}}\right)$ (Figure $\mathrm{S} 5$ and Table S3 in the SI). On the basis of the connectivity of carboxylate groups and bridging hydroxyl ligands, the 1-D rod-shaped inorganic SBUs are generated (Figure 1a), which can be viewed as the cornersharing arrangement of two types of metal-carboxylate clusters, $\left[\mathrm{CoO}_{6}\right](\mathrm{A})$ and $\left[\mathrm{Co}_{2} \mathrm{O}_{10}\right](\mathrm{B})$, in a sequence of $-\mathrm{A}-\mathrm{B}-\mathrm{A}-$. Each type Acluster is the coordination polyhedra of Co1, and a pair of edge-sharing coordination polyhedra of $\mathrm{Co} 2$ form type B cluster (Figure 1a). The Co $\cdots$ Co separations linked by the hydroxyl ligand are 3.14, 3.54, and 3.58 $\AA$ (Figure S6 in the SI). The final 3-D framework is formed by the linkage of adjacent rod-shaped SBUs and TPTA ligands (Figure 1b). By linking the carboxylate Catoms, the 1-D rod-shaped SBU is simplified to a twisted zigzag ladder (Figure S7 in the SI). Each TPTA ligand links four adjacent 1-D rod-shaped SBUs and can be considered as a 4-connected node. Thus, the 3-D framework can be 


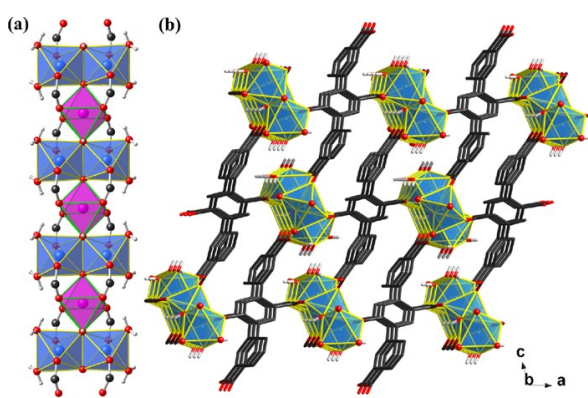

Figure 1. Views of (a) the 1-D rod-shaped SBU in 2 (the Col and

$\mathrm{Co} 2$ ions are depicted as polyhedra in pink and blue) and (b) the 3-D structure constructed from 1-D rod-shaped SBUs and TPTA ligands.

simplified as a $(4,4)$-connected $\left(4^{2} .6^{3} .8\right) 4\left(6^{2} .8^{4}\right)$ topology, calculated by the TOPOS program (Figure S8 in the SI). ${ }^{12}$

From the magnetic view, the 3-D coordination polymer contains three $\mathrm{Co}^{\mathrm{II}}$ ions in the repeating unit in complex $2\left(\mathrm{Co}^{\mathrm{II}}\right)$. The three $\mathrm{Co}^{\mathrm{II}}$ ions are bridged by a $\mu_{3}-\mathrm{OH}^{-}$group, with three distinct $\mathrm{Co}-\mathrm{O}-\mathrm{Co}$ angles of 98,119 , and $117^{\circ}$, which result in a ferromagnetic interaction and two antiferromagnetic interactions in the trinuclear unit (Figure $\mathrm{S} 6$ in the SI). The chains align along the $b$ axis of the unit cell and then are linked in a 3-D coordination polymer by TPTA ligands (Figure S9 in the SI). The magnetic coupling through TPTA ligands is very weak, with the shortest interchain separation being $9.7 \AA$. Magnetic susceptibility data collection for complex $2\left(\mathrm{Co}^{\mathrm{II}}\right)$ were in the range of $2-300 \mathrm{~K}$ with a 3000 $\mathrm{G}$ applied dc field. The data are depicted in a X $T$ vs $T$ plot in Figure 2 and $X$ vs $T$ plot in Figure S10 of the SI.

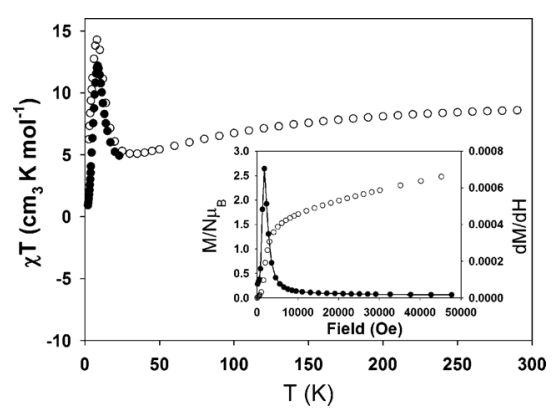

Figure 2. $\mathrm{X} T$ vs $T$ plot of $2\left(\mathrm{Co}^{\mathrm{II}}\right)$ at 200 Oe applied fields (black circles) and $3000 \mathrm{Oe}$ (white circles). Inset: Magnetization vs field plot of $2\left(\mathrm{Co}^{\mathrm{II}}\right)$ at $2 \mathrm{~K}$ (white circles). The black line and scatter plot is the first derivative of the magnetization vs field at $2 \mathrm{~K}$; the maximum shows the inflection point of the $\mathrm{M}$ vs $\mathrm{H}$ curve.

The $X T$ product has a value of $8.6 \mathrm{~cm}^{3} \mathrm{~K} \mathrm{~mol}^{-1}$ at $300 \mathrm{~K}$. The expected value for three $\mathrm{Co}^{\mathrm{II}}$ ions $(S=3 / 2$ and $g=2.0)$ would be $5.625 \mathrm{~cm}^{3} \mathrm{~K} \mathrm{~mol}^{-1}$, since the $\mathrm{Co}^{\mathrm{II}}$ ions are in a distorted octahedral environment. They display strong spin-orbit coupling, and the experimentally observed $\mathrm{X} T$ product is around $3.2 \mathrm{~cm}^{3} \mathrm{~K} \mathrm{~mol}^{-1}$ per $\mathrm{Co}^{\mathrm{II}}$ ion, in accordance with the value observed from $2\left(\mathrm{Co}^{\mathrm{II}}\right)$. Effectively, at low temperatures each $\mathrm{Co}^{\mathrm{II}}$ ion has an effective spin of $1 / 2$. The chains can be described as shown in Scheme S2 of the SI as anisotropic ferrimagnetic chains, where a ferromagnetically coupled $\left[\mathrm{Co}^{\mathrm{II}}\right]_{2}$ unit with effective $S=1$ alternates with a single $\mathrm{Co}^{\mathrm{II}}$ ion with value arrives at $14.3 \mathrm{~cm}^{3} \mathrm{~K} \mathrm{~mol}^{-1}$ at $8 \mathrm{~K}$. Susceptibility data were also measured at $200 \mathrm{G}$ below $30 \mathrm{~K}$ (see the black dots in Figure 2 and Figure S10 in the SI). The susceptibility vs $T$ plot (Figure $\mathrm{S} 10$ in the $\mathrm{SI}$ ) shows a maximum at $7 \mathrm{~K}$ for the data collected with a 200 Oe applied field. Below $8 \mathrm{~K}$, a sharp drop occurs, due to the magnetic transition to an antiferromagnetically coupled state. The magnetization vs field measurement at $2 \mathrm{~K}$ (Figure 2 inset) displays a characteristic S-shape, indicating a transition at 1700 Oe from a state with no net spin to a paramagnetic state. This field is directly related to the antiferromagnetic interaction that leads to the magnetic transition. A plot of $\ln (\mathrm{X} T)$ vs $1 / T$ is shown in Figure 3,

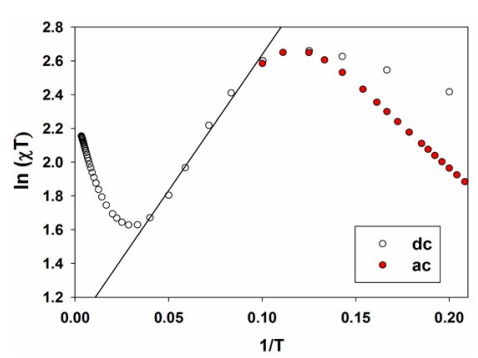

effective $S=1 / 2$. The $X T$ product slowly drops along with the temperature decreases and reaches a minimum at $30 \mathrm{~K}$. Below this temperature, there is a quick increase and the maximum 
Figure $3 . \ln (\mathrm{X} T)$ vs $1 / T$ plot for $2\left(\mathrm{Co}^{\mathrm{II}}\right)$ with ac data (red circles) and dc data (white circles), showing the activated region between 20 and $10 \mathrm{~K}$. The linear regression fitting form obtained from the energy to create a domain wall along the chain is depicted as the solid line.

which indicates the activated behavior of the $\mathrm{X} T$ product of $2\left(\mathrm{Co}^{\mathrm{II}}\right)$ for its one-dimensional nature of the chains that form the 3-D structure. The linear region observed is characteristic of a 1-D chain with Ising-like anisotropy. The value at $16 \mathrm{~K}$ of the slope of the linear region indicates the energy that is required to form domain walls. The maximum observed is most likely caused by the intrachain antiferromagnetic (AF) coupling.

The individual chains are weakly coupled in the 3-D structures, but the antiferromagnetic order does, not preclude the SCM behavior, as shown before by Clerac et al. and others. ${ }^{13-16}$ Data of ac magnetic susceptibility plots are collected at frequencies in the range from 910 to 1500 $\mathrm{Hz}$ with an alternating ac field of 4 Oe (Figure 4). The chains behave as SCM, and the ac data shown in Figure 4 display maxima in the out-of-phase magnetic susceptibility that are frequency dependent.

Complex $1\left(\mathrm{Ni}^{\mathrm{II}}\right)$ is isostructural to $2\left(\mathrm{Co}^{\mathrm{II}}\right)$, containing $\mathrm{Ni}^{\mathrm{II}}$ instead of $\mathrm{Co}^{\mathrm{II}}$ ions. Magnetic measurement parameters for complex $1(\mathrm{Ni})$ were similar to those of complex 2(Co). The $\mathrm{X} T$ value at $300 \mathrm{~K}$ is $3.7 \mathrm{~cm}^{3} \mathrm{~K} \mathrm{~mol}^{-1}$, which is similar to the theoretical value for three $\mathrm{Ni}^{\mathrm{II}}$ ions $(S=1$ and $g=2.2)$, which would be $3.6 \mathrm{~cm}^{3} \mathrm{~K} \mathrm{~mol}^{-1}$ (Figure $\mathrm{S} 11)$. In the whole stage of temperature reduction, the $\mathrm{X} T$ product remains unchanged before $50 \mathrm{~K}$, but then, a sharp drop arises. Thus, the data are not field dependent, which indicates a very weak coupling between the $\mathrm{Ni}^{\text {II }}$ ions that form the $3-\mathrm{D}$ structure of $1\left(\mathrm{Ni}^{\mathrm{II}}\right)$. The coupling scheme should be very similar to that of $2\left(\mathrm{Co}^{\mathrm{II}}\right)$, with $\mathrm{Ni}-\mathrm{O}-\mathrm{Ni}$ angles of $98.59^{\circ}, 120.04^{\circ}$, and $119.51^{\circ}$ and a $\mathrm{Ni}-\mathrm{O}-\mathrm{O}-\mathrm{Ni}$ torsion angle of $180^{\circ}$. These values result in a ferromagnetic interaction and two antiferromagnetic interac- tions in the trinuclear unit but slightly more AF than the $\mathrm{Co}$ (II) case due to the larger angles. The torsion angle of the $\mathrm{Ni}_{2} \mathrm{O}_{2}$ diamond of $180^{\circ}$ facilitates stronger antiferomagnetic inter- actions, ${ }^{17}$ as reported by Christou and co-workers in 1995, while the Ni-O-Ni angle of more than $98^{\circ}$ is already in the 

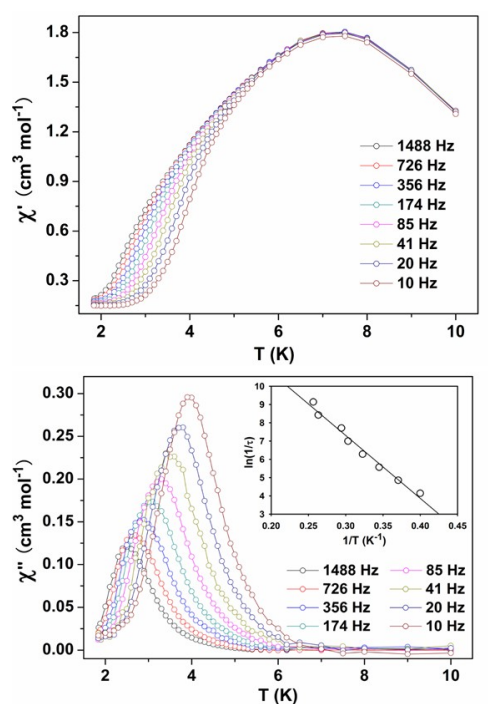

Figure 4. In-phase (top) and out-of-phase (bottom) ac magnetic susceptibility plots for $2\left(\mathrm{Co}^{\mathrm{II}}\right)$ at ac frequencies of $1488,726,356,174$, $85,41,20$, and $10 \mathrm{~Hz}$. The solid line in the inset figure shows the leastsquares fit of the experimental data according to the Arrhenius equation.

limit between the ferromagnetic and antiferromagnetic interaction, so the coupling should be very weak. Overall, the magnetic coupling in $1\left(\mathrm{Ni}^{\mathrm{II}}\right)$ is dominated by a combination of weak interactions. Magnetization vs field measurement at $2 \mathrm{~K}$ shows a steady rise with applied field typical of weak magnetic interactions leading to a nonisolated ground state (Figure S12 in the $\mathrm{SI}$ ). The $\mathrm{Ni}^{\mathrm{II}}$ ion is not as anisotropic as the $\mathrm{Co}^{\mathrm{II}}$ ion, and the SCM behavior and magnetic transition observed for $\mathrm{Co}^{\mathrm{II}}$ are not present in the isostructural $\mathrm{Ni}^{\mathrm{II}}$ complex.

Two neutral 3-D complexes comprising 1-D rod-shaped inorganic SBUs are presented here. They are crystallographically isomorphic and coordinatively isostructural with the magnetized relaxation phenomenon in a SCM and the antiferromagnetic coupling in a 1-D inorganic chain. The results above are useful to recognize the magnetic behaviors in coordination frameworks and give instructions for the design of new magnetic materials.

\section{ASSOCIATED CONTENT}

\section{Supporting Information}

The Supporting Information is available free of charge on the ACS Publications website at DOI: 10.1021/acs.inorgchem.5b02716.

Experimental details, tables, structural figures, and details about magnetic measurements for 1 and 2 (PDF) Crystallographic data (CIF)

\section{AUTHOR INFORMATION}

\section{Corresponding Authors}

*E-mail: chunsenliu@,zzuli.edu.cn.

*E-mail: dumiao@public.tpt.tj.cn.

Notes

The authors declare no competing financial interest.

\section{ACKNOWLEDGMENTS}

This work received support from the NSFC (National Natural Science Foundation of China: 21171151, 21471134, and
21571158), Program for Science \& Technology Innovative Research Team in University of Henan Province (15IRTSTHN-002), Innovation Scientists and Technicians Troop Construction Projects of Henan Province (152101510003), and Plan for Scientific Innovation Talent of Henan Province (154200510011). E.C.S. is grateful for the financial support from the Spanish Government (Grant CTQ2012-32247).

\section{REFERENCES}

(1) (a) Gatteschi, D.; Sessoli, R.; Villain, J. Molecular Nanomagnets; Oxford University Press: Oxford, 2006. (b) Zheng, Y.-Z.; Zheng, Z.; Chen, X.-M. Coord. Chem. Rev. 2014, 258-259, 1-15. (c) Urdampilleta, M.; Klayatskaya, S.; Ruben, M.; Wernsdorfer, W. ACSNano 2015, 9, 4458-4464. (d) Chen, M.; Sanudo, E. C.; Jiméez, E.; Fang, S.-M.; Liu, C.-S.; Du, M. Inorg. Chem. 2014, 53, 6708-6714. (e) Saber, M. R.; Dunbar, K. R. Chem. Commun. 2014, 50, 12266-12269.

(2) (a) Lópz-Cabrelles, J.; Giménz-Marques M.; Espallargas, G. M.; Coronado, E. Inorg. Chem. 2015, 54, 10490-10496. (b) Liu, C.-S.; Du, M.; Sañudo, E. C.;Echeverria, J.; Hu, M.;Zhang, Q.;Zhou, L.-M.; Fang, S.-M. Dalton Trans. 2011, 40, 9366-9369.

(3) Glauber, R. J. J. Math. Phys. 1963, 4, 294-307.

(4) (a) Liu, J.; Qu, M.; Rouzieres, M.; Zhang, X.-M.; Clerac, R. Inorg. Chem. 2014, 53, 7870-7875. (b) Vaz, M. G. F.; Cassaro, R. A. A.; Akpinar, H.; Schlueter, J. A.; Lahti, P. M.; Novak, M. A. Chem. - Eur.J. 2014, 20, 5460-5467.

(5) Liu, X.-T.; Wang, X.-Y.; Zhang, W.-X.; Cui, P.; Gao, S. Adv Mater. 2006, 18, 2852-2856.

(6) (a) Aono, Y.; Yoshida, H.; Katoh, K.; Breedlove, B. K.; Kagesawa, K.; Yamashita, M. Inorg. Chem. 2015, 54, 7096-7102. (b) Wang, T.T.; Ren, M.; Bao, S.-S.; Liu, B.;Pi, L.; Cai,Z.-S.;Zheng,Z.-H.; Xu,Z.L.; Zheng, L.-M. Inorg. Chem. 2014, 53, 3117-3125.

(7) (a) Kajiwara, T.; Tanaka, H.; Nakano, M.; Takaishi, S.; Nakazawa Y.; Yamashita, M. Inorg. Chem. 2010, 49, 8358-8370. (b) Kajiwara, T.; Nakano, M.; Kaneko, Y.; Takaishi, S.; Ito, T.; Yamashita, M.; IgashiraKamiyama, A.; Nojiri, H.; Ono, Y.; Kojima, N. J. Am. Chem. Soc. 2005, 127, 10150-10151.

(8) (a) Bernot, K.; Bogani, L.; Caneschi, A.; Gatteschi, D.; Sessoli, R. J. Am. Chem. Soc. 2006, 128, 7947-7956. (b) Zheng, Y.-Z.; Lan, Y.; Wernsdorfer, W.; Anson, C. E.; Powell, A. K. Chem. - Eur. J. 2009, 15, $12566-12570$

(9) (a) Wang, Y.-Q.; Sun, W.-W.; Wang, Z.-D.; Jia, Q.-X.; Gao, E.-Q.; Song, Y. Chem. Commun. 2011, 47, 6386-6388. (b) Hu, B.-W.;Zhao, J.-P.; Yang, Q.; Zhang, X.-F.; Evangelisti, M.; Sañudo, E. C.; Bu, X.-H. Dalton Trans. 2010, 39, 11210-11217.

(10) (a) Zhao, J.-P.; Yang, Q.; Liu, Z.-Y.; Zhao, R.; Hu, B.-W.; Du, M.; Chang, Z.; Bu, X.-H. Chem. Commun. 2012, 48, 6568-6570. (b) Ma, X.; Zhang, Z.; Shi, W.; Li, L.; Zou, J.; Cheng, P. Chem. Commun. 2014, 50, 6340-6342.

(11) (a) Ren, H.-Y.; Yao, R.-X.; Zhang, X.-M. Inorg. Chem. 2015, 54, 6312-6318. (b) Wu, Y.; Yang, G.-P.; Zhou, X.; Li, J.; Ning, Y.; Wang, Y.-Y. Dalton Trans. 2015, 44, 10385-10391. (c) Wu, Y.; Yang, G.-P.; Zhao, Y.; Wu, W.-P.; Liu, B.; Wang, Y.-Y. Dalton Trans. 2015, 44 3271-3277.

(12) Blatov, V. A.; Shevchenko, A. P. TOPOS-Version 4.0 professional (beta evaluation); Samara State University: Samara, Russia, 2006. (13) Jeon, I.-R.; Clerac, R. Dalton Trans. 2012, 41,9569-9586.

(14) Yang, C.-I.; Tsai, Y.-J.; Hung, S.-P.; Tsai, H.-L.; Nakano, M. Chem. Commun. 2010, 46, 5716-5718.

(15) Sun, H.-L.; Wang, Z.-M.; Gao, S. Coord. Chem. Rev. 2010, 254 1081-1100.

(16) Dhers, S.; Feltham, H. L. C.; Brooker, S. Coord. Chem. Rev. 2015, 296, 24-44.

(17) Halcrow, M. A.; Sun, J.-S.; Huffman, J. C.; Christou, G. Inorg Chem. 1995, 34, 4167-4177. 